\title{
Electrodeposition of Cyclic Multilayer Zn-Co Films Using Square Current Pulses and Investigations on Their Corrosion Behaviors
}

\author{
Ramesh S. Bhat ${ }^{1}$, A. Chitaranjan Hegde ${ }^{2 *}$ \\ ${ }^{1}$ Nitte Mahalinga Adyanthaya Memorial Institution of Technology (NMAMIT), Nitte, India \\ ${ }^{2}$ National Institute of Technology Karnataka, Surathkal, India \\ Email: "hegdeac@rediffmail.com
}

Received May 13, 2012; revised June 21, 2012; accepted July 12, 2012

\begin{abstract}
The cyclic multilayer alloy (CMA) coatings of Zn-Co have been developed galvanostatically on mild steel (MS), using single bath technique. Depositions were carried out using square current pulses. Corrosion behaviors of the coatings were evaluated by potentiodynamic polarization and electrochemical impedance method, supported by dielectric spectroscopy. The cyclic cathode current densities (CCCD's) and number of layers were optimized for highest corrosion stability of the coatings. The CMA coating developed at 3.0/5.0 A/ $\mathrm{dm}^{2}$, having 300 layers, represented as (Zn-Co $)_{3.0 / 5.0 / 300}$ was found to exhibit $\sim 40$ times better corrosion resistance compared to monolayer coating, developed from same bath for same time. Substantial improvement in the corrosion resistance of CMA coatings is attributed to layered coating, having alternatively different phase structures, evidenced by XRD study. The formation of multilayer and corrosion mechanism was analyzed using Scanning Electron Microscopy.
\end{abstract}

Keywords: CMA Zn-Co Coatings; Corrosion Resistance; Dielectric Spectroscopy; X-Ray Diffraction (XRD); Scanning Electron Microscopy (SEM) Study

\section{Introduction}

The composition modulated multilayer alloy, or simply, cyclic multilayer alloy (CMA) coatings, are basically consisting of successive layers of alloys having two/or more compositions [1]. They may be developed from a single bath containing two/or metals ions, by proper simulation of cathode current densities, using sophisticated power sources [2-4]. CMA coatings consist of a large number of thin alternate alloy layers, and each layer plays its own distinctive role in achieving preferred performances. The development of zinc-based CMA coatings for the protection of steel substrates has been investigated recently [3-5], and were found to exhibit the enhanced corrosion performance. Kirilova et al. reported the anodic behavior of composition modulated Zn-Co multilayer, electrodeposited from single and dual baths [6]. The coatings were developed under different conditions of current density, and their anodic behaviors were studied. CMA coatings obtained from a single bath was found to dissolve at potentials between the dissolution potentials of pure $\mathrm{Co}$ and pure $\mathrm{Zn}$ coatings. Zinc and $\mathrm{Zn}-\mathrm{Ni}$ alloy CMA coatings were electrodeposited on to a steel subs-

"Corresponding author. trate by the successive deposition of zinc and Zn-Ni alloy sub layers from dual baths [7]. The coated samples were evaluated in terms of the surface appearance, surface and cross-sectional morphologies, as well as corrosion resistance. The layered structure and the existence of micro cracks caused by the internal stress in the thick $\mathrm{Zn}-\mathrm{Ni}$ alloy sublayers were observed. CMA coatings were found to be more corrosion-resistant than the monolithic coatings of zinc or $\mathrm{Zn}-\mathrm{Ni}$ alloy of same thickness. The possible reasons for the better protective performance of $\mathrm{Zn}-\mathrm{Ni} / \mathrm{Zn} \mathrm{CMA}$ coatings were given on the basis of the analysis of micrographic features of zinc and $\mathrm{Zn}-\mathrm{Ni}$ alloy. A probable corrosion mechanism of zinc and $\mathrm{Zn}-\mathrm{Ni}$ alloy CMA coatings was also proposed. The zinc sub layers beneath the $\mathrm{Zn}-\mathrm{Ni}$ alloy top layer was found to dissolve through the pores and micro-cracks existing in the $\mathrm{Zn}-\mathrm{Ni}$ alloy deposits existing during corrosion.

Varieties of zinc and $\mathrm{Zn}$-Co alloy CMA coatings were electrodeposited onto steel substrates using dual bath technique [8]. The experimental results showed that the zinc and Zn-Co alloy CMA coatings were more corrosion-resistant than corresponding monolithic coatings of same thickness. The development of zinc and zinc-alloy based coatings was reviewed by Wilcox $[9,10]$. The 
principle of productions of CMA coatings, concentrating on their applications as protective coatings for metal surfaces was examined. Zn-Ni, Zn-Fe, Zn-Co and Zn-Mn alloy coatings was reported, to deposit in multilayer format. Electrodeposition methods, bath chemistries, coating morphologies, and their performances against corrosion were also reviewed. Most of the work reported above, explains the development of CMA Zn-M (M=Ni, $\mathrm{Co}$ and $\mathrm{Fe}$ ) coating using double bath technique (DBT), in which successive layers of alternating composition was obtained from two separate electrolytes having either pure $\mathrm{Zn}^{2+}$ and $\mathrm{M}^{2+}$ ions, or $\mathrm{Zn}^{2+}$ and $\left(\mathrm{Zn}^{2+}+\mathrm{M}^{2+}\right)$ ions. The deposition conditions were optimized and results were discussed. The coating behaviors were evaluated either by their dissolution potentials or by $\mathrm{E}_{\text {corr }}$ values, without quantifying their corrosion rates. In this direction, Thangaraj et al. [11,12] reported optimization of an acid chloride bath for production of CMA Zn-Co coating, showing the highest corrosion stability.

In this work, it is attempted to develop a stable bath having thiamine hydrochloride (THC) as additives, and to optimize the deposition conditions for peak performance of the coatings against corrosion. The corrosion rates were calculated from Tafel extrapolation method, supported by electrochemical impedance method. The role of $\mathrm{THC}$, in modulation of composition was tried to identify by cyclic voltammetry (CV) study. The optimization of deposition conditions, in terms of cathode current densities and number of layers for development of CMA Zn-Co coating and its characterization, concentrating on their application as protective coatings on MS are reported.

\section{Experimental}

To begin with, the bath constituents and operating parameters, for deposition of monolithic (monolayer) coatings of $\mathrm{Zn}$-Co were optimized using direct current (DC), following the standard Hull cell method [13]. THC is a water-soluble B-complex vitamin, freely soluble in water and is reportedly compatible with many metal ions. Compatibility is dependent upon factors such as $\mathrm{pH}$, concentration, temperature and diluents used. CA is a colourless crystalline organic compound, one of the carboxylic acids. The optimal cathode current density, $\mathrm{pH}$ and concentration of each constituent were arrived, based on the brightness (visual observation), homogeneity and adhesion (tape test) of coatings. The bath composition arrived is: $50 \mathrm{~g} / \mathrm{L} \mathrm{ZnSO} \cdot 7 \mathrm{H}_{2} \mathrm{O}, 15 \mathrm{~g} / \mathrm{L} \mathrm{CoSO}_{4} \cdot 7 \mathrm{H}_{2} \mathrm{O}, 60 \mathrm{~g} / \mathrm{L}$ $\mathrm{CH}_{3}-\mathrm{COONa}, 4 \mathrm{~g} / \mathrm{L} \mathrm{C}_{6} \mathrm{H}_{8} \mathrm{O}_{7} \cdot \mathrm{H}_{2} \mathrm{O}(\mathrm{CA})$, and $0.5 \mathrm{~g} / \mathrm{L}$ $\mathrm{C}_{12} \mathrm{H}_{17} \mathrm{~N}_{4} \mathrm{OSCl} \cdot \mathrm{HCl}$ (THC) and optimal $\mathrm{pH}$ and temperature are respectively, $4^{\circ} \mathrm{C}$ and $30^{\circ} \mathrm{C}$. The electrolyte was prepared using LR-grade chemicals and distilled water.
A PVC cell of $250 \mathrm{~cm}^{3}$ capacity was used for electroplating, with cathode anode space of $\sim 5 \mathrm{~cm}$. The anode was pure $\mathrm{Zn}$ with the same exposed area. The pre-cleaned mild steel (MS) panels with $7.5 \mathrm{~cm}^{2}$ active surface area were used as cathode. All depositions (monolayer and multilayered) were carried out using DC Power Analyzer (AGILENT, N6705A), and subsequent electrochemical characterizations were made using potentiostat/galvanostat (VersaSTAT3, Princeton Research). All coatings were carried out for $10 \mathrm{~min}$ for comparison purpose. After deposition, the electrode was rinsed with distilled water, and used for further investigation.

Cyclic Voltammetry (CV) study was performed in a conventional three-electrode cell to better understand the kinetics of electrodeposition, and to identify the role of additives, namely THC and CA. Pure platinum foil with a surface area of $1 \mathrm{~cm}^{2}$ was used as working electrode. Before each experiment, the electrode was activated by immersion in 1:1 $\mathrm{HNO}_{3}$. The $\mathrm{CV}$ experiments were conducted in a quiescent solution, without purging. Initially, three scan rates were evaluated viz. 10, 20 and 50 $\mathrm{mV} \cdot \mathrm{s}^{-1}$, in order to identify which scanning rate gives a better readability of data. The choice fell on the 10 $\mathrm{mV} \cdot \mathrm{s}^{-1}$ scan rate and therefore the remaining tests were carried out at this scan rate only. The scan began from 0 $\mathrm{V}$ in the positive direction, up to $+0.5 \mathrm{~V}$. Then, the scan was reversed to the negative direction, down to $-1.5 \mathrm{~V}$, and finally reversed back to $+0.5 \mathrm{~V}$. The phase structure of the electrodeposits under different c.d. was analyzed using X-ray Diffractometer (Bruker AXS) using CuK $\alpha$ radiation, $(\lambda=1.5405 \mathrm{~A}, 30 \mathrm{kV})$. Scanning Electron Microscopy (SEM), Model JSM-6380 LA from JEOL, Japan, was used to examine the multilayer formation and its deterioration after corrosion. Generally, the direct current resulted in the coatings having constant composition, called monolithic coatings. But, periodic change in the current density allowed the growth of layers on substrate with periodic change in the chemical compositions [9]. i.e. Pulses of low current density results in layers of low Co content, and pulses of high current density results in layers of high Co content. The instrument was set to cycle between two different cathode current densities, called cyclic cathode current densities (CCCD's) in repetitive way. While the thickness of the each layer was controlled by the duration of each pulse, the composition of each layer is decided by the current density applied. The total number of layers was fixed appropriately by adjusting the time for each cycle. Thus, CMA coatings of different configurations were produced. Such multilayer coatings are hereafter represented as $(\mathrm{Zn}-\mathrm{Co})_{1 / 2 / \mathrm{n}}$, where ( $\mathrm{Zn}-\mathrm{Co})$ represents alloy of $\mathrm{Zn}$ and $\mathrm{Co}$, and 1 and 2 represent the cathode current density that is made to cycle between, and " $n$ " represents the total number of layers 
formed during total deposition time (10 $\mathrm{min}$ ).

The corrosion behavior of coatings was measured by electrochemical DC and AC techniques, in a three-electrode configuration cell. All electrochemical potentials referred in this work are indicated relative to $\mathrm{Ag} / \mathrm{AgCl} /$ $\mathrm{Cl}_{\text {sat }}^{-}$electrode. The $5 \% \mathrm{NaCl}$ solution $\left(30^{\circ} \mathrm{C}\right)$ was used as corrosion medium, throughout this study. Potentiodynamic polarization behavior was studied in a potential ramp of $\pm 250 \mathrm{mV}$ from open circuit potential (OCP) at scan rate of $1 \mathrm{mV} \cdot \mathrm{s}^{-1}$. The corrosion rates of the coatings were evaluated by the equation,

$$
\begin{aligned}
\mathrm{CR}= & 0.0033 \times \mathrm{i}_{\text {corr }}\left(\mu \mathrm{A} \cdot \mathrm{cm}^{-2}\right) \\
& \times \frac{\text { Eq. wt. of alloy }(\mathrm{g})}{\text { density of the alloy }\left(\mathrm{g} \cdot \mathrm{cm}^{-3}\right)} \mathrm{mm} \cdot \mathrm{y}^{-1}
\end{aligned}
$$

where CR is the corrosion rate, in $\mathrm{mm} \cdot \mathrm{y}^{-1}$ and $\mathrm{i}_{\text {corr }}$ is the corrosion current density. Electrochemical Impedance spectroscopy (EIS) study was carried out in the frequency limit from $100 \mathrm{kHz}$ to $20 \mathrm{mHz}$. Before corrosion study, the open circuit potential (OCP) for each test specimen was fixed. This is accomplished by immersing it in corrosion medium for $300 \mathrm{sec}$ to reach equilibrium potential. The chemical composition of the coatings was determined by stripping the known amount of electrodeposit into $2 \mathrm{~N} \mathrm{HCl}$, and $\mathrm{wt} \%$ Co was estimated colorimetrically [14]. While thicknesses of the coatings were estimated by Faraday's law, it was verified by measurements, using a Digital Thickness Meter (Coatmeasure, Model M \& C).

\section{Results and Discussions}

\subsection{Cyclic Voltammetric Study}

$\mathrm{CV}$ is the universal electrochemical technique, used either to understand the electrode kinetics or to elucidate reaction mechanisms, including the quantitative analysis. The technique consists of varying the electrode potential in a linear fashion between two limits [15]. It was observed that $\mathrm{THC}$ in combination with $\mathrm{CA}$ has significant effect on the homogeneity and brightness of the coatings. Hence, the process and product of $\mathrm{Zn}-\mathrm{Co}$ deposition was studied by $\mathrm{CV}$ method, on adding $\mathrm{CA}$ and THC, individually and in combination, into the electrolytic bath. In absence of $\mathrm{CA}$, the electrochemical oxidation curve showed multiple peaks, as shown in Figure 1(a). This corresponds to the dissolution of the metals in the alloy via. different intermediate phases [16]. After adding CA, a small change in the shape of the voltammogram was found (Figure 1(b)). It indicates that CA has not involved in complexation of metal ions. Further, when THC was added, the shape of voltammogram changed drastically, with one major peak at $-0.80 \mathrm{~V}$ and one minor peak at $-0.30 \mathrm{~V}$, corresponding to dissolution of alloys at two different phases (Figure 1(c)). Lastly, when CA and THC were added in combination, the intensity of the first peak has increased with slight distortion to the right (Figure 1(d)). Hence, it may be inferred that THC improves the deposit character, by forming complex with metal ions, and CA is acting as brightener, by getting reinforced into crystal lattice by the action of THC [17].

\subsection{X-ray Diffraction Study}

The corrosion resistance of $\mathrm{Zn}$-Co alloy depends practically on the $\mathrm{wt} \% \mathrm{Co}$ in the deposit, and consequently, its phase structure depending on c.d. employed for its deposition [18-23]. Hence, an effective modulation in composition can be achieved by successive layering of alloys having distinct phase difference, by proper selection of CCCD's. This is accomplished by taking the XRD patterns of Zn-Co alloy (monolayer) developed from the same bath, at different current densities. Accordingly, the XRD patterns of Zn-Co alloy at different c.d. are shown in Figure 2. It may be observed that the intensity of the peak corresponding $\mathrm{Zn}$ (110) increases progressively with c.d. (from $2.0-5.0 \mathrm{~A} / \mathrm{dm}^{2}$ ), and has reached maximum at $5.0 \mathrm{~A} / \mathrm{dm}^{2}$. In addition to this, reflections corresponding Zn (101) and Zn (110) have become more distinct with increase of current density. Further, the peak corresponding to $\mathrm{Zn}$ (100) was observed as the current density was increased from $2.0 \mathrm{~A} / \mathrm{dm}^{2}$ to $5.0 \mathrm{~A} / \mathrm{dm}^{2}$. Thus, $\mathrm{X}$-ray diffraction study clearly indicates that the variation in cathodic current density brings significant change in phase structure of coatings, allowing the better modulation in composition, in conjunction with number layers.

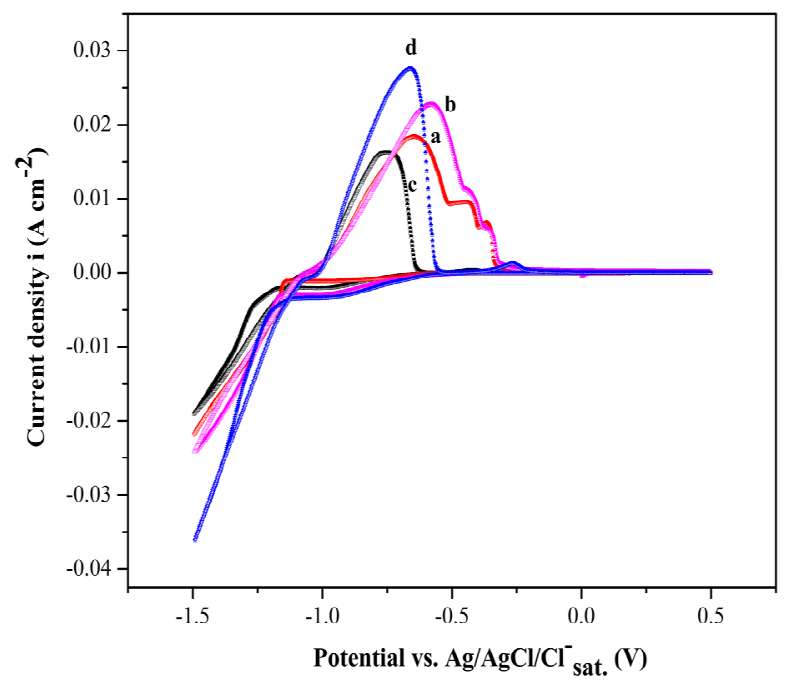

Figure 1. Cyclic voltammograms for $\mathrm{Zn-Co}$ alloy bath, demonstrating the effects of THC. Working electrode: Pt, $\mathrm{pH}=4.0, \mathrm{~T}=30^{\circ} \mathrm{C}, \mathrm{v}=10 \mathrm{mV} \cdot \mathrm{s}^{-1}$, (a) Without additive; (b) With CA; (c) With THC; (d) With THC + CA. 


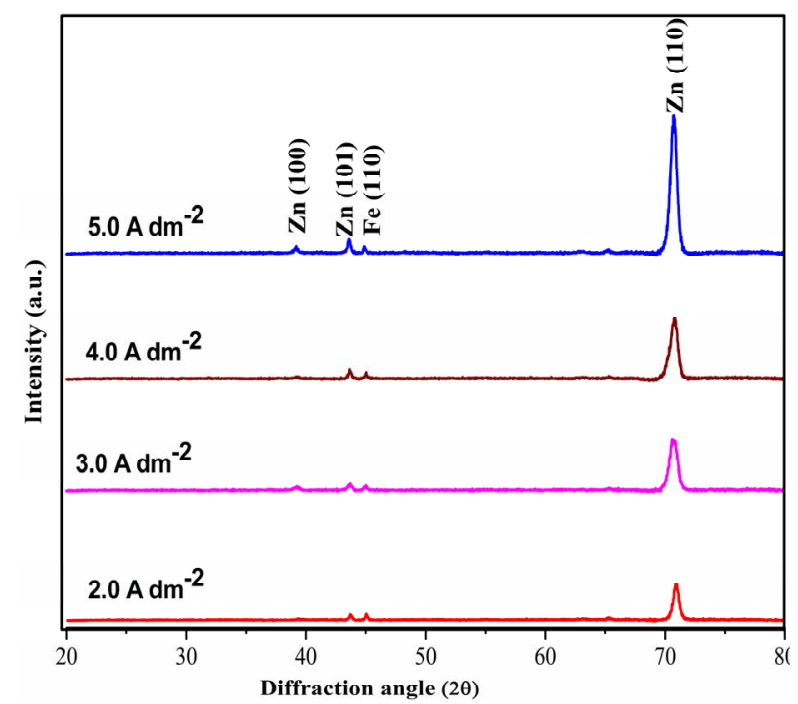

Figure 2. X-ray diffraction profiles of electrodeposits obtained on MS from optimal bath at different current density as mentioned on the plot.

\subsection{Monolithic Zn-Co Coating}

Wide spectrum of Zn-Co alloy formed on Hull cell panel showed that current density (c.d.) plays an important role in deciding the properties of the deposit. The effects of c.d. on wt $\%$ Co, thickness, corrosion rate (CR) and appearance of the coatings were reported in Table 1. The corrosion data showed that the coating at $4.0 \mathrm{~A} / \mathrm{dm}^{2}$ is found to be bright, with least corrosion rate $\left(7.08 \times 10^{-2}\right.$ $\mathrm{mm} \cdot \mathrm{y}^{-1}$ ), compared to coatings at other current densities. Hence, it has been taken as its optimal corrosion rate.

\subsection{CMA Zn-Co Coating}

\subsubsection{Optimization of Cyclic Current Densities}

The electrochemical deposition of CMA coatings was accomplished by galvanodynamic cycling of the working electrode between pre-set current ranges in an aqueous solution containing $\mathrm{Zn}^{2+}$ and $\mathrm{Co}^{2+}$ ions. As mentioned earlier, even a small change in the $\mathrm{wt} \%$ of $\mathrm{Zn}-\mathrm{Co}$ alloy may result in significant properties change due to change in the phase structure. Initially, multilayer alloy coatings having 10 layers were developed at different sets of CCCD's to increase their corrosion resistance. Among the various sets tried, the less corrosion rate was measured in the coatings produced with difference of $3.0 \mathrm{~A} / \mathrm{dm}^{2}$, between CCCD's (i.e. at 2.0/5.0 A/ $/ \mathrm{dm}^{2}$ and 3.0/5.0 $\mathrm{A} / \mathrm{dm}^{2}$ ). These coatings were found to be bright and uniform. This combination of CCCD's has been selected for studying the effect of layering, as described in the following section and in Table 2.

Table 1. Effect of current density on the deposit characters of monolithic Zn-Co alloy.

\begin{tabular}{cccccccc}
\hline c.d. $\left(\mathrm{A} / \mathrm{dm}^{2}\right)$ & $\mathrm{wt} \% \mathrm{Co}$ & $\begin{array}{c}\text { Thickness } \\
(\mu \mathrm{m})\end{array}$ & $\begin{array}{c}\text { Vickers Hardness } \\
\mathrm{V}_{100}\end{array}$ & $\begin{array}{c}\mathrm{E}_{\text {corr }}(\mathrm{V}) \mathrm{vs} . \\
\mathrm{Ag} / \mathrm{AgCl} / \mathrm{Cl}_{\text {sat }}\end{array}$ & $\begin{array}{c}\mathrm{i}_{\text {corr }}\left(\mu \mathrm{A} \cdot \mathrm{cm}^{-2}\right) \\
\mathrm{CR} \times 10^{-2}\left(\mathrm{~mm} \cdot \mathrm{y}^{-1}\right)\end{array}$ & $\begin{array}{c}\text { Appearance of the } \\
\text { deposit }\end{array}$ \\
\hline 1.0 & 0.39 & 8.2 & 152 & -1.295 & 6.57 & 9.64 & Grayish white \\
2.0 & 0.46 & 10.6 & 185 & -1.302 & 5.768 & 8.46 & Grayish \\
3.0 & 0.60 & 13.5 & 195 & -1.300 & 5.221 & 7.66 & Bright \\
4.0 & 1.06 & 17.7 & 259 & -1.290 & 4.831 & 7.08 & Bright \\
5.0 & 1.08 & 209 & 276 & -1.335 & 5.362 & 7.86 & Porous \\
\hline
\end{tabular}

Table 2. Effect of overall number of layering on corrosion properties of $\mathrm{Zn}$-Co CMA coatings obtained with $2.0-5.0 \mathrm{~A} / \mathrm{dm}^{2}$ and 3.0 - 5.0 A/dm² CCCD's.

\begin{tabular}{|c|c|c|c|c|c|c|}
\hline Coating configuration & $\begin{array}{c}\text { Number of } \\
\text { layers }\end{array}$ & $\begin{array}{c}\text { Deposition time for } \\
\text { each layer }(\mathrm{sec})\end{array}$ & $\begin{array}{l}\text { Average thickness } \\
\text { of layer (nm) }\end{array}$ & $\begin{array}{c}\text { Ecorr (V) vs. } \\
\mathrm{Ag} / \mathrm{AgCl} / \text { Clsat }\end{array}$ & $\mathrm{i}_{\text {corr }} / \mathrm{A} \cdot \mathrm{cm}^{-2}$ & $\begin{array}{l}\mathrm{CR} \times 10^{-2} \\
\left(\mathrm{~mm} \cdot \mathrm{y}^{-1}\right)\end{array}$ \\
\hline \multirow{6}{*}{$(\mathrm{Zn}-\mathrm{Co})_{2.0 / 5.0}$} & 10 & 60 & 2500 & -1.101 & 2.975 & 4.33 \\
\hline & 20 & 30 & 1250 & -1.086 & 1.804 & 2.63 \\
\hline & 60 & 10 & 417 & -1.151 & 1.019 & 1.48 \\
\hline & 120 & 5 & 208 & -1.112 & 0.789 & 1.15 \\
\hline & 300 & 2 & 83 & -1.116 & 0.234 & 0.34 \\
\hline & 600 & 1 & 41 & -1.110 & 5.697 & 8.36 \\
\hline \multirow{6}{*}{$(\mathrm{Zn}-\mathrm{Co})_{3.0 / 5.0}$} & 10 & 60 & 2500 & -1.149 & 1.777 & 2.58 \\
\hline & 20 & 30 & 1250 & -1.197 & 1.286 & 1.87 \\
\hline & 60 & 10 & 417 & -1.195 & 0.512 & 0.75 \\
\hline & 120 & 5 & 208 & -1.196 & 0.276 & 0.40 \\
\hline & 300 & 2 & 83 & -1.198 & 0.108 & 0.16 \\
\hline & 600 & 1 & 41 & -1.194 & 3.51 & 5.15 \\
\hline
\end{tabular}




\subsubsection{Optimization of Overall Number of Layers}

The properties of CMA electrodeposits, including their corrosion resistance, may often to be improved by increasing the total number of layers (usually, up to an optimal number), as long as the adhesion between layers is not deteriorated. Therefore, at the optimal combination of current densities $\left(3.0 / 5.0 \mathrm{~A} / \mathrm{dm}^{2}\right)$, CMA coatings with 10 , $20,60,120,300$, and 600 layers were produced. As observed in Table 2, the corrosion rate decreased drastically as the overall number of layers increased only up to 300 layers, and then increased. The lowest corrosion rate $\left(0.16 \times 10^{-2} \mathrm{~mm} \cdot \mathrm{y}^{-1}\right)$ was observed for a multilayer coatings, represented by $(\mathrm{Zn}-\mathrm{Co})_{3.0 / 5.0 / 300}$ configuration, while for the same number of layers at CCCD's of 2.0/5.0 $\mathrm{A} / \mathrm{dm}^{2}$, the corrosion rate was $0.34 \times 10^{-2} \mathrm{~mm} \cdot \mathrm{y}^{-1}$, which is more when compared to the earlier. Hence, CMA $(\mathrm{Zn}-\mathrm{Co})_{3.0 / 5.0 / 300}$ configuration, is taken as optimal. From the total observed thickness (about $25 \mu \mathrm{m}$ ), the average thickness of each layer in $(\mathrm{Zn}-\mathrm{Co})_{3.0 / 5.0 / 300}$ coating was calculated. For this configuration, the average thickness of each layer is found to be $\sim 83.0 \mathrm{~nm}$, as shown in Table 2 .

The corrosion rate was found to increase at higher degree of layering (i.e. $>300$ layers), shown in Table 2. This may be attributed to the less relaxation time for redistribution of metal ions at the diffusion layer, during plating [17]. The phenomenon may be explained as follows: During plating, metal ions from the bulk of the electrolyte diffuse towards the cathode and to get discharge as metal atom, and this process of diffusion is mainly controlled by the cathode current density. As the number of layers increased, the time for the deposition of each layer, say, $(\mathrm{Zn}-\mathrm{Co})_{1}$ is small (as the total time for deposition remains same, $10 \mathrm{~min}$ ). At higher degree of layering, there is no sufficient time for metal ions to relax (against diffusion under given current density) and to get deposit on cathode, with modulation in composition. In other words, the cathode current density is cycling so fast that ions cannot diffuse towards cathode with modulation. As a result, at higher degree of layering modulation in composition is not likely to take place, or CMA deposit is tending towards monolayer with less corrosion stability.

\subsection{Corrosion Study}

\subsubsection{Tafel's Polarization Study}

Potentiodynamic polarization curves of CMA ( $\mathrm{Zn}-\mathrm{Co})_{3.0 / 5.0}$ coating with different number of layers is shown in Figure 3. Tafel extrapolation on such curves resulted in determination of the corrosion potential, $\mathrm{E}_{\text {corr }}$ corrosion current density, $\mathrm{i}_{\text {corr }}$ and corrosion rate, $\mathrm{CR}$ as listed in Table 2. The progressive decrease of corrosion current density $\left(\mathrm{i}_{\text {corr }}\right)$ with number of layers indicated that improved corrosion resistance is due to layering of alloys, having distinct properties. It may be observed that the passivation current of $\mathrm{Zn}$-Co coatings remained almost same, regardless of the number of layers. This indicates that the improved corrosion resistance is not due to the corrosion product formed, but due to the delayed, or blocked path of corrosion agent, due to layering, as will be discussed later. Polarization curve shown in Figure 3 demonstrates that CMA coating with $(\mathrm{Zn}-\mathrm{Co})_{3.0 / 5.0 / 300}$ configuration is the most corrosion resistant.

\subsubsection{Electrochemical Impedance Spectroscopy}

Though potentiodynamic polarization technique is used to study the kinetics of an electrode reaction, the result is often corrupted by side effects such as the charging currents of the double layer observed on a time-scale of the order of a millisecond, or by the ohmic drop associated to the experimental setup [15]. The response of reversible electrochemical systems studied in the presence of an ohmic drop unfortunately resembled the response of kinetically slow systems. The best way of differentiating the kinetics of an electrode reaction from experimental side effects is to use an excitation function covering a large time domain. The most common of these techniques is EIS where the electrode potential excitation function is a sine wave of variable frequencies [24]. Accordingly, the corrosion behavior of the coatings can be assessed, in terms of electrical double layer (EDL) capacitor model, with treating the substrate and medium as parallel plates, and the coating in between them, as dielectrics of the capacitor. When AC signal of small amplitude of \pm 10 $\mathrm{mV}$ is applied over a wide frequency limit are used, the impedance data points obtained are the response of the corrosion circuit, consisting of capacitance $\mathrm{C}$, inductance,

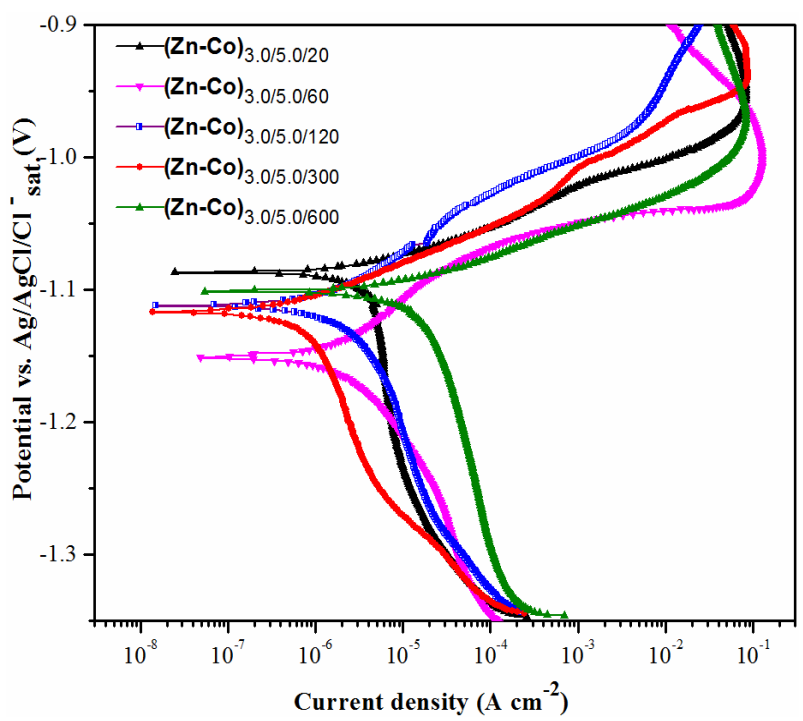

Figure 3. Potentiodynamic polarization curves of CMA $(\mathrm{Zn}-\mathrm{Co})_{3.0 / 5.0}$ coatings with different number of layers at scan rate $1 \mathrm{mV} \cdot \mathrm{s}^{-1}$. 
$\mathrm{L}$ and resistance, $\mathrm{R}$. The impedance data points obtained, over the wide range of frequency is indicative of its corrosion stability. Figure 4 shows the EIS Nyquist plots of $(\mathrm{Zn}-\mathrm{Co})_{3.0 / 5.0}$ coatings, with different number of layers. Impedance signals clearly indicate that the polarization resistance, $R_{P}$ of the coatings increased progressively with the number of layers (up to 300 layers), and then decreased (600 layers).

\subsection{Dielectric Spectroscopy}

The EIS data points can be used to calculate the relative permittivity, $\varepsilon_{r}$ of the coatings from film thickness, $\delta$ and area, $\mathrm{A}$ and capacitance $\mathrm{C}$, using the equation

$$
\varepsilon_{r}=\frac{\mathrm{C}_{\mathrm{c}} \delta}{\mathrm{A} \varepsilon_{0}}
$$

where, $\varepsilon_{0}$ is permittivity of the vacuum. Improved corrosion resistance of CMA coatings can be explained in terms of the effect of time dependent electric field (i.e. frequency response). Figure 5 shows the variation of relative permittivity versus frequency, of the coatings having different number of layers. It was observed that the value of $\varepsilon_{r}$ for all coatings is high at low frequency which are diminished as the frequency is increased. At low frequency side, the decrease of $\varepsilon_{r}$ with increase of number of layers indicates that the dielectric barrier of coatings has increased with layering. This attributes to the increased interfacial polarization effect, caused by the heterogeneous media consisting of phases with different dielectric permittivity [25]. There are many causes for heterogeneity in materials, but concerning the CMA coatings discussed in present work is related to interfaces created by layering. Thus it may be summarized as the peak corrosion resistance of CMA $(\mathrm{Zn}-\mathrm{Co})_{3.0 / 5.0 / 300}$ coating is due to the decreased permittivity of the coating.

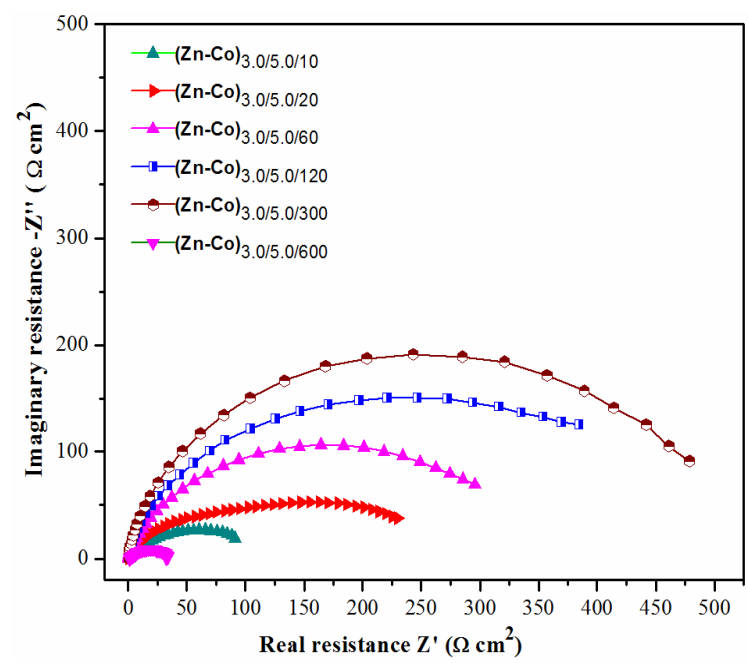

Figure 4. Nyquist plots of CMA Zn-Co coating system with $(\mathrm{Zn}-\mathrm{Co})_{3.0 / 5.0}$ configuration having different number of layers.

\subsection{Comparison between Monolayer and CMA Zn-Co Coatings}

On comparing the corrosion rate of $(\mathrm{Zn}-\mathrm{Co})_{3.0 / 5.0 / 300}$, given in Table 2, with that of monolayer $\mathrm{Zn}-\mathrm{Co}$ alloy, at 4.0 $\mathrm{A} / \mathrm{dm}^{2}$ (Table 1), it was found that the CMA coating is $\sim 40$ times higher corrosion resistant. Potentiodynamic polarization behaviors of monolithic and CMA coatings (under optimal conditions) is shown in Figure 6. A drastic decrease of corrosion current, $i_{\text {corr }}$ was observed when the coating pattern was changed from monolayer to multilayer type. The high corrosion resistance of CMA coatings can be envisaged as, the failures like pores, crevices occurring in one layer is blocked or neutralized by the successively deposited coating layers, and thus the corrosion agent's

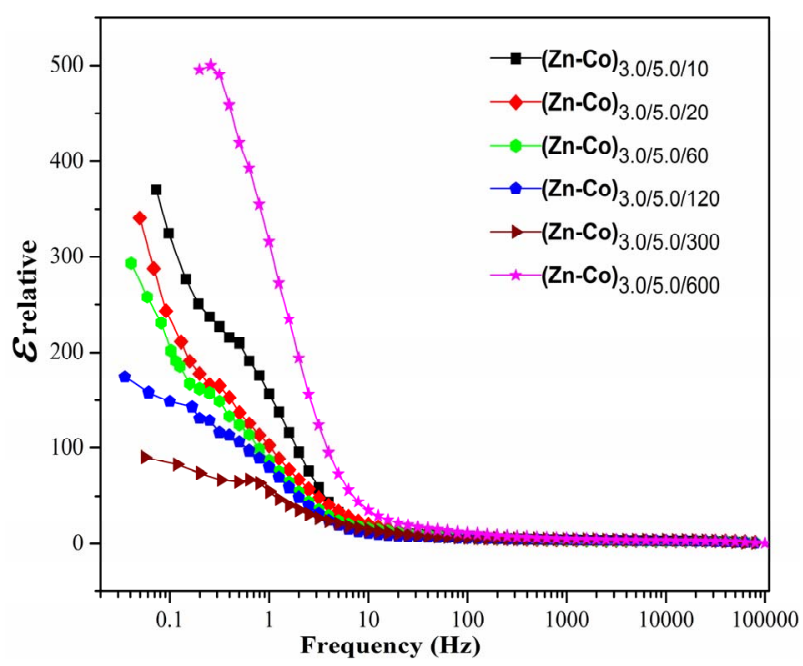

Figure 5. Relative permittivity of CMA $(\mathrm{Zn}-\mathrm{Co})_{3.0 / 5.0}$ coatings with varying number of layers as function of frequency.

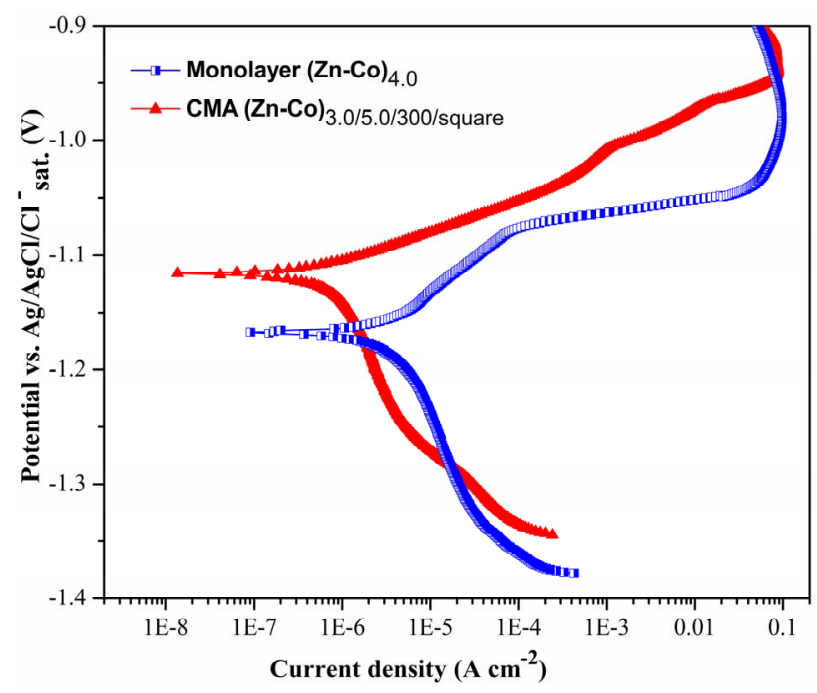

Figure 6. Comparison of polarization behaviors of monolayer $(\mathrm{Zn}-\mathrm{Co})_{4.0}$ alloy and CMA $(\mathrm{Zn}-\mathrm{Co})_{3.0 / 5.0}$ coatings of same thickness. 
path is delayed or blocked. The improved corrosion resistance afforded by CMA coating can also explained in terms of the formation of alternate layers of alloys with low and high wt $\%$ of Co. In other words, the protection efficacy of CMA Zn-Co coatings is due to barrier effect of $\mathrm{Zn}$-Co alloy layer with high wt\% Co and the sacrificial effect of Zn-Co alloy layer with low wt $\%$ Co [8]. A small compositional change in alternate layers, corresponding to deposits at 3.0 and $5.0 \mathrm{~A} / \mathrm{dm}^{2}$ has brought a significant change in the phase structure of the alloys, as evidenced by XRD study [26].

\subsection{SEM Study}

Surface morphology of monolithic alloy coatings, marked as Figure 7(a), displayed a uniform and crack-free morphology. Formation of alternate layers of alloys having distinctive properties was confirmed by SEM. Cross sectional view of $(\mathrm{Zn}-\mathrm{Co})_{3.0 / 5.0 / 10}$ is shown in Figure 7(b). The poor contrast may be due to marginal difference in chemical composition $\left(0.60 \mathrm{wt} \% \mathrm{Co}\right.$ at $3.0 \mathrm{~A} / \mathrm{dm}^{2}$ and $1.08 \mathrm{wt} \% \mathrm{Co}$ at $5.0 \mathrm{~A} / \mathrm{dm}^{2}$ ) of alloys in each layer. Inspection of the microscopic appearance of surface, after corrosion tests was used to demonstrate the formation of successive layers of alloys, during deposition and to understand the reason for improved corrosion resistance. By subjecting the coating to dissolve by corrosion test, a region displaying the layers, with distinction can be obtained. This has been accomplished by the anodic polarization up to $+250 \mathrm{mV}$ vs. OCP in $5 \% \mathrm{NaCl}$. Then the corroded specimen was washed with distilled water and examined, under SEM. Figure 7(c) exhibits CMA $(\mathrm{Zn}-\mathrm{Co})_{3.0 / 5.0 / 10}$, after corrosion test. Hence, it may inferred that the increased corrosion stability of CMA coatings is due to successive layers of alloys having different degree of pores and cracks, which allowed the selective dissolution of metals in alternate layers with low and high $w \mathrm{t} \%$ of $\mathrm{Co}$.

\section{Conclusions}

- CMA coatings of Zn-Co have been developed on MS by proper manipulation of cathodic current densities and number of layers.

- CV study demonstrated that THC improves the deposit character by forming complex with metal ions, and $\mathrm{CA}$ acts as brightener by getting reinforced into the crystal lattice by the action of THC.

- The XRD study revealed that the improved corrosion resistance afforded by CMA coating is due to alternate layers of alloys, having different phase structures.

- The CMA (Zn-Co) coating, having 300 layers, deposited at 3.0 and $5.0 \mathrm{~A} / \mathrm{dm}^{2}$ found to show the least corrosion rate $\left(0.16 \times 10^{-2} \mathrm{~mm} \cdot \mathrm{y}^{-1}\right)$ compared to that of monolithic alloy $\left(7.08 \times 10^{-2} \mathrm{~mm} \cdot \mathrm{y}^{-1}\right)$ of same thick- ness.

- Corrosion resistance of CMA coating increased with number of layers only up to a certain optimal level (300 layers) and then decreased.

- Increase of corrosion rate at higher number of layers is attributed to less relaxation time for redistribution of metal ions $\left(\mathrm{Zn}^{2+}\right.$ and $\left.\mathrm{Co}^{2+}\right)$ at the diffusion layer, during deposition. In other words, at higher layering the CMA coating tends to become monolithic.

SEM analysis confirms the formation of multilayer during deposition, and evidenced the extended protection by successively deposited alloy coating layers having different degree of pores and crevices.
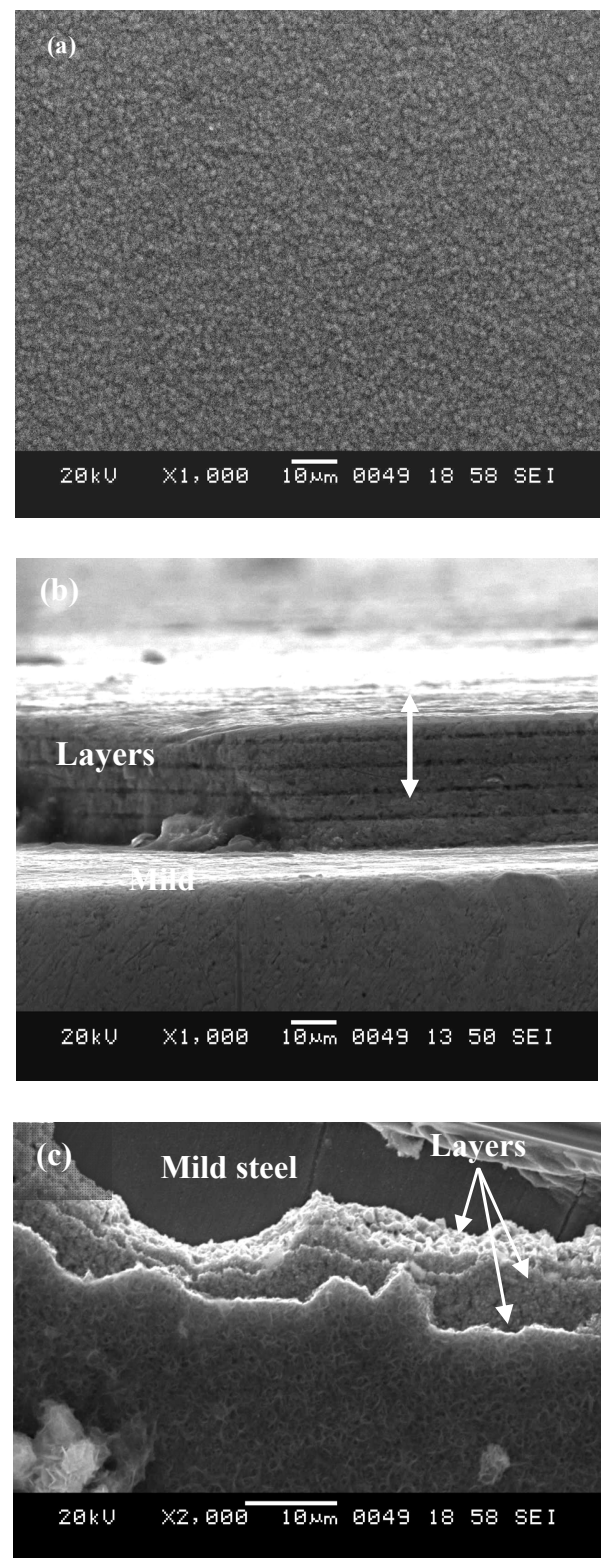

Figure 7. SEM image of monolayer Zn-Co alloy deposit (a), CMA (Zn-Co) 3.0/5.0/10 coating (b); Cross sectional view after corrosion test displaying the layer formation (c). 


\section{REFERENCES}

[1] G. Chawa, G. D. Wilcox and D. R. Gabe, "Compositionally Modulated Zinc Alloy Coatings for Corrosion Protection," Transaction Institute of Metal Finishing, Vol. 76, 1998, pp. 117-121.

[2] D. R. Gabe, "Protective Layered Electrodeposits," Electrochimica Acta, Vol. 39, No. 8-9, 1994, pp. 1151-1121. doi:10.1016/0013-4686(94)E0025-U

[3] I. Ivanov and I. Kirilova, "Corrosion Resistance of Compositionally Modulated Multilayered Zn-Ni Alloys Deposited from Single Bath," Journal of Applied Electrochemistry, Vol. 33, No. 3-4, 2003, pp. 239-244. doi:10.1023/A:1024179032045

[4] M. R. Kalantary, G. D. Wilcox and D. R. Gabe, "Production of Compositionally Modulated Alloys by Simulated High Speed Electrodeposition from a Single Solution," Electrochimica Acta, Vol. 40, No. 11, 1995, pp. 16091616. doi:10.1016/0013-4686(95)00085-S

[5] I. Ivanov, T. Valkova and I. Kirilova, "Corrosion Resistance of Compositionally Modulated Zn-Ni Multilayers Electrodeposited from Dual Bath," Journal of Applied Electrochemistry, Vol. 32, No. 1, 2002, pp. 85-89. doi:10.1023/A:1014259326912

[6] I. Kirilova, I. Ivanov and St. Rashkov, "Anodic Behaviour of Composition Modulated Zn-Co Multilayers Electrodeposited from Single and Dual Baths," Journal of Applied Electrochemistry, Vol. 28, No. 6, 1998, pp. 13591363. doi:10.1023/A:1003210404884

[7] J. Y. Fei, G. Z. Liang, W. L. Xin and W. K. Wan, "Surface Modification with Zinc and Zn-Ni Alloy Compositionally Modulated Multilayer Coatings," Journal of Iron and Steel Research, International, Vol. 13, No. 4, 2006, pp. 61-67. doi:10.1016/S1006-706X(06)60080-0

[8] J. Y. Fei, G. Z. Liang, W. L. Xin and J. H. Liu, "Corrosion Performance of Zinc and Zinc-Cobalt Alloy Compositionally Modulated Multilayer (CMM) Coatings," Journal of Wuhan University of Technology, Materials Science Edition, Vol. 21, No. 4, 2006, pp. 40-44.

[9] G. D. Wilcox, "Surface Modification with Compositionally Modulated Multilayer Coatings," Journal of Corrosion Science and Engineering, Vol. 6, 2004, pp. 52-56.

[10] S. S. Chatha, H. S. Sidhu and B. S. Sidhu, "Characterisation and Corrosion Erosion Behaviour of Carbide Based Thermal Spray Coating," Journal of Minerals and Materials Characterization and Engineering, Vol. 11, No. 6, 2012, pp. 569-586.

[11] V. Thangaraj, N. Eliaz and A. Chitharanjan Hegde, "Corrosion Behavior of Composition Modulated Multilayer Zn-Co Electrodeposits Produced Using a Single-Bath Technique," Journal of Applied Electrochemistry, Vol. 39, No. 3, 2009, pp. 339-345. doi:10.1007/s10800-008-9677-1

[12] S. Samal, A. Bhattaacharyya and S. K. Mitra, "Study on Corrosion behaviour of Pearlitic Rail Steel," Journal of Minerals and Materials Characterisation and Engineering, Vol. 10, No. 7, 2011, pp. 573-581.
[13] N. V. Parthasaradhy, "Practical Electroplating Hand Book," Prentice Hall Inc., Upper Saddle River, 1989.

[14] A. I. Vogel, “Quantitative Inorganic Analysis," Longmans Green and Co., London, 1951.

[15] H. Hubert Girault, "Analytical and Physical Electrochemistry," EPFL Press Swiss Publishing Company Distributed by Marcel Dekker, Inc., New York, 2004.

[16] G. Trejo, R. Ortega, Y. Meas, E. Chainet and P. Ozil, "Effect of Benzylideneacetone on the Electrodeposition Mechanism of Zn-Co Alloy," Journal of Applied Electrochemistry, Vol. 33, No. 5, 2003, pp. 373-379. doi:10.1023/A:1024466604939

[17] N. Kanani, "Electroplating Basic Principles, Processes and Practice," Elsevier Ltd., Berlin, 2006.

[18] M. M. Younan, "Surface Microstructure and Corrosion Resistance of Electrodeposited Ternary Zn-Ni-Co Alloy," Journal of Applied Electrochemistry, Vol. 30, No. 1, 2000, pp. 55-60. doi:10.1023/A:1003840519591

[19] F. Elkhatabi, M. Sarret, and C. Muller, "Chemical and Phase Compositions of Zinc-Nickel Alloys Determined by Stripping Techniques," Journal of Electroanalytical Chemistry, Vol. 404, No. 1, 1996, pp. 45-53. doi:10.1016/0022-0728(95)04359-4

[20] G. Barcelo, E. Garcia, M. Sarret and C. Muèller, "Characterization of Zinc-Nickel Alloys Obtained from an Industrial Chloride Bath," Journal of Applied Electrochemistry, Vol. 28, No. 10, 1998, pp. 1113-1120. doi:10.1023/A:1003461109203

[21] J. B. Bajat, M. D. Maksimovic, V. B. Miskovic-Stankovic, and S. Zec, "Electrodeposition and Characterization of Zn-Ni Alloys as Sublayers for Epoxy Coating Deposition," Journal of Applied Electrochemistry, Vol. 31, No. 3, 2001, pp. 355-361. doi:10.1023/A:1017580019551

[22] A. Petrauskas, L. Grinceviciene, A. Cesuniene and R. Juskenas, "Influence of $\mathrm{Co}^{2+}$ and $\mathrm{Cu}^{2+}$ on the Phase Composition of Zn-Ni Alloys," Electrochimica Acta, Vol. 51, No. 27, 2006, pp. 6135-6139. doi:10.1016/j.electacta.2006.01.064

[23] J. B. Bajat and V. B. Miskovic-Stankovic, "Protective Properties of Epoxy Coatings Electrodeposited on Steel Electrochemically Modified by Zn-Ni Alloys," Progress in Organic Coatings, Vol. 49, No. 3, 2004, pp. 183-196. doi:10.1016/j.porgcoat.2003.09.019

[24] X. Yuan, C. Song, H. Wang and J. Zhang, "Electrochemical Impedance Spectroscopy in PEM Fuel Cells Fundamentals and Applications," Springer Publications, London, 2010. doi:10.1007/978-1-84882-846-9

[25] P. J. Gellings and H. J. M. Bouwmeester, "Handbook of Solid State Electrochemistry," CRC Press, The Netherlands, 1997.

[26] P. Ganeshan, P. Swaminatha, Kumaraguru and B. N. Popov, "Development of Compositionally Modulated Zn-Ni Multilayer Deposits as Replacement for Cadmium," Surface Coating and Technology, Vol. 201, No. 18, 2007, pp. 7896-7904. doi:10.1016/j.surfcoat.2007.03.033 